\title{
LA SERNA
}

\section{Y EL DERECHO ADMINISTRATIVO}

$(*)$

Excelentísimos señores; señoras y señores: Henos aquí a la gran familia administrativa, bajo el augusto patriarcado. de don José Gascón y Marín, para conmemorar los primeros. cien años de la ciencia jurídico-administrativa. En la tarde de ayer, voces autorizadas pusieron de relieve la importancia que tenía el estudio de la ciencia de la administración y del Derecho administrativo hace ya un siglo. Nos corresponde en el día de hoy hacer una especie de recensión retrospectiva. sobre una de las figuras de este centenario: don Pedro Gómez de la Serna; y hemos de acometer esta labor en un espacio muy reducido de tiempo, porque consideraciones de orden personal y científico hacen que debamos reducir nuestra intervención para que podáis escuchar más holgadamente y con menos fatiga de atención, disertaciones más meritorias e interesantes que la mía.

Don Pedro Gómez de la Serna corresponde a ese plantel de juristas prolíficos y enciclopédicos. Es su obra de una tal pluralidad de facetas que a veces asusta un poco. Dirige $y$ colabora la gran Enciclopedia de Derecho y Administración, que empieza a publicarse el año 1848 y termina en 1870 , conocida por otro nombre con el de. "Nuevo Teatro universal de la legislación de España e Indias". Comprende ésta 12 volúmenes. Funda y codirige con Reus la Revista general de Legislación y Jurisprudencia; es Catedrático de Derecho romano, civil, penal; posteriormente explica Legislación comparada. Entre sus obras, posiblemente son sus "Instituciones de Derecho administrativo", las que tienen un menor relie-

(*) Conferencia pronunciada en las Sesiones de Esturdio dedicadas al Centenario do jos fundajores de la ciencia juridico-administrativa española. 
ve, y por ello, son más conocidos, con toda probabilidad, sus libros de Derecho romano, de civil y penal (I), sus Tratados de Der cho procesal, sus Comentarios de legislación positiva. Pero, además, tenemos otra faceta de Gómez de la Serna: ingresa como Académico en la Real de la Historia por un discurso sobre el reinado de Alfonso el Sabio; finalmente, como hombre que descuella en la vida administrativa, es Ministro de la Gobernación, Ministro de Gracia y Justicia, desempeña la Presidencia del Tribunal Supremo (en 1869), la Fiscalia Suprema de Justicia, también es Consejero de Estado, amén de otros cargos, Diputado, Senador, etc.

$\mathrm{Su}$ libro "Instituciones de Derecho administrativo" se publica en 1843 , en esa época incipiente que podemos llamar de incubación de nuestra ciencia del Derecho administrativo, época de gestación, de labor preparatoria, en la que tanto el Derecho positivo como la doctrina auguran ya una futura e inmediata especialización. Empieza a escribir estas Instituciones en el año 40, y lo hace con ese estilo claro, brillante, propio de la literatura jurídica de la época, cuando ya el castellano legal se había emancipado un poco del estilismio y barroquismo forense de épocas pretéritas y cuando, como decía un ilustre compañero nuestro, los profesores de Derecho todavía no sabían alemán. Este libro sencillo, sin pretensiones, tiene, a nuestro entender, una grave imputación que hacer, $y$ es su falta de noticias informativas. No se cita a nadie, ni a los clásicos. Parece que Castillo de Bobadilla, Vives, Menchaca, etc., no habían existido; ni siquiera cita a otros más próximos a su época, como Jovellanos, Javier de Burgos, Oliván, etc. Tampoco encontramos ninguna breve referencia a los que pudiéramos llamar "primitivos" del Derecho administrativo francés, y que evidentemente influyen en él, aunque hay que reconocer que la influencia de los españoles es más importante. Al libro de Gómez de la Serna se le pudiera objetar este requisito que hace unos años anunciara un filósofo español (2), como indispensable en un libro de ciencia;

(1) Los Elementos de Derecho civil y penal, escritos en colaboración con Montalbán alcanzan, que yo sepa, hasta 14 ediciones. También fué abjeto de variadas ediciones el Tratado académico fonerse.

(2) J. Ortega Gasset, Obras completas: Origenes del esplañol, pág. 963. 
indicaba aquél que todo libro de ciencia, en primer lugar, debía ser un libro, pero también debía contener ciencia, y, en verdad, que en algunos casos la obra de la Serna no parece que sea una obra muy científica, sino más bien una reproducción exegética de la legislación: Sin embargo, hay que tener en cuenta que todos los libros, aun los que nos parecen peor concebidos, aquellos que puedan verse como llenos de errores en alguna de sus partes o en alguno de sus capítulos, tienen siempre cierta utilidad. Los libros de ciencia son como el faro, que unas veces sirve de guía para anunciar la proximidad de un puerto seguro y otras anuncia obstáculos, parajes de los que debe uno alejarse, y en este sentido la obra de la Serna es también bastante aleccionadora. Así, pues, nosotros la traemos a colación en el día de hoy, tanto para poner de manifiesto lo que pudiéramos llamar aspecto científico de este libro como para anunciar algunos de los errores que, en nuestro sentir, en dicho libro exsiten.

Como todas las obras del Derecho administrativo, correspondientes a esta etapa preparatoria, la parte general aparece un poco descuidada. Desde luego, en ella campea una preocupación dogmática con el sistema de división de poderes. El régimen de división de poderes pudiéramos decir que es como el principio científico de sus instituciones. Sin embargo, hay que hacer notar que La Serna, como ayer el maestro Gascón nos recordaba en relación con Oliván, revela ciertos vestigios de división funcional, póniendo de realce la trascendencia de esta división funcional; hasta podríamos reconocer en cierto pasaje un principio de jerarquía de poderes. En la relación entre éstos distingue en un aspecto formal lo que llama acto de soberanía, la.ley y los actos de la magistratura, que son los propios de la administración. Establece la actividad administrativa como una actividad continua, como opuesta a la legislativa, que es siempre más lenta, mucho más meditada, y entre estos caracteres de acción administrativa señala cómo, en cierto respecto, el acto administrativo tiene características de acto contencioso.

Alude a los conflictos de competencia y dice que su resolución, más que prerrogativa real, es un deber que incumbe al Poder ejecutivo. En la parte orgánica aboga por un Con- 385 
sejo de Estado-entonces, el año 43, no se había creado el: Consejo Real-que pusiera a cubierto al Monarca, en momen-tos críticos, de opiniones de oposición, etc., y dice que debeser no sólo órgano de consulta, sino también órgano contencioso-administrativo. Por último, ofrecen interés en la parte: orgánica sus referencias acerca de los órganos activos y deliberantes y de las Direcciones generales, que deben ser "ele-. mentos científicos y especializados" para auxiliar a los Ministros.

Pero, naturalmente, donde encontramos mayor númera. de datos y una mayor madurez sistemática es en lo que en la actualidad llamamos materia administrativa o parte especial. Esta materia administrativa se trata con cierta extensión, a: veces con excesiva extensión, en cuestiones que propiamente hoy día no se estudian en lo administrativo, como, porejemplo, lo electoral. En relación con asuntos típicamenteadministrativos se abordan, con harta minucia, algunos de ellos; verbigratia: al hablar de teatros. En la policía deteatros, comprendida dentro de la de espectáculos, y la más. amplia de la policía de costumbres de su libro, se alude desde la censura de las obras dramáticas a las cuestiones de "propiedad intelectual", propiedad literaria de las mismas. Se hace referencia a los bailes de máscaras, a las corridas de toros (predice la desaparición de lo que hoy llamamos la fies-ta nacional). Sin embargo, otras veces sistematiza a ciertas: materias que estamos viviendo en los momentos actuales. Voy a leer dos pasajes muy breves en su libro. Uno, al hablar del problema de las subsistencias, de la libertad en el tráfico de subsistencias. Alli, respondiendo a la ideología de la. época, defiende, como es lógico, la tesis de la libertad abso-luta. "Errores antiguos de economía política, dice (I), consagraron el funesto sistema de las tasas e introdujeron leyes: crueles de represión para castigar a los que traficaban en artículos de subsistencias.

Los resultados acreditaron la ineficacia de este sistema, durante el cual casi nunca bastaron las cosechas a las necesidades del país, y casi siempre se vendieron las subsistencias.

(1) T. I, pág. 227. 
a un precio muy superior al que hubieran tenido abandonadas a si mismas."

(V. art. 3 de la instrucción para los subdelegados de Fomento de 30 de noviembre de I933.)

En otro de sus capítulos, por ejemplo, al hablar de los problemas de la segunda enseñanza, también merece, no que haga yo unas alusiones a la crítica de la legislación de entonces, sino que vosotros oigáis por mi voz lo que él escribia en 1840 , porque el 43 es en realidad cuando se publicó su libro, pero ya advierte al principio que fué en esa primera época cuando terminó la obra.

"La instrucción secundaria privada tiene entre nosotros grande latitud... El no exigirse garantías a los profesores, la libertad absoluta que thenen los directores de montar sus establecimientos con independencia absoluta del Gobierno $y$ de sus agentes, y la facilidad que se ha dado de incorporar los estudios en las universidades, no sufriendo los alumnos examen hasta después de haber experimentado una pérdida de tiempo irreparable, han producido en todos la convicción de la necesidad de la reforma, pues que es tardía e ineficaz la inspección que se ha reservado al Gobierno por medio de visitadores" (I).

En otros capítulos de la obra aparecen también cuestiones de gran interés; por ejemplo, el de la policía municipal o policía urbana, que por cierto no se inserta en la parte que pudiéramos llamar de administración local, sino en la policía en general; en ella se citan especialmente pasajes de la "Novísima Recopilación", sobre trazado de calles, alineación, rotulación, empedrado y limpieza de las mismas, sobre obras públicas municipales, ornato, etc.; sus doctrinas. se ofrecen sazonadas con citas de aquel ordenamiento legal, que entonces era el verdadero Código administrativo. Precisamente en el momiento en que escribe su obra es cuando comienza a disgregarse de este cuerpo legal una serie de disposiciones aisladas y fragmentarias que han dado lugar a toda esa balumba que después se conoce con el nombre de legislación administrativa.

(I) Instituciones. T. II, págs. $244-45$. 
Se lamenta, en las primeras páginas del libro, de la dificultad que presenta el conocimiento de esta masa de legislación, y para ello propone una serie de remedios, remedios que aparecen recogidos, no en las Instituciones, sino en un artículo que publicara años después en la "Revista de Legislación y Jurisprudencia", donde, como solución para evitar estos conflictos, para facilitar el conocimiento del Derecho administrativo y para resolver dudas sobre vigencia de disposiciones, propone el que se creen unas comisiones que estudien por separado los diversos capítulos del Derecho administrativo y redacten una especie de compilación en donde apareciera lo fundamental y el derecho aplicable en cada rama (I).

Otras propuestas, otras sugerencias muy interesantes apa-

(1) Sobre las colecciones legislativas. Revista General de Legishación y Jurisprudencia. T. XVII, pág. 465.

Página 466: "Toda la legislación no está en los cuadernos a que por convenio general se les da el nombre de Códigos; su parte más voluminosa no consiste en las leyes del orden civil y penal, y en las que arreglan los procedimientos, sino en las que se refieren a los intereses colectivos de la sociedad."

Son éstas las que cuidan de los servicios y del dominio priblico, organizan la beneficencia, crean y administran todos los 'establecimientos de utilidad general, das fomento a la agricultura, a la inddustria, a las artes y al comercio, alientan con recompensas los grandes merecimientos, dan vida a las obras públicas sin desatender los intereses monales $y$ perpetuos the la sociedad, tales como el rulto religioso y la instrucción de las genenaciones que viemen...

Es frecuente, añalde, que "haya disposiciones de la misma clase que no han salido nunca a la luz pública y permaneciendo siempre sepultadas en un archivo sólo som conocidas por los empleados de algunas dependencias".

No es fácil "poder jactarse, después del más profundó estudio, de haber llegado a apurar toda la parte legislativa de una materia determinada de las muchas que corresponden al orden administrativo. $Y$ si se apura, y si, como sucede, es muy complicarda la legislación, entonces entran otras dificultades y dudas gravísimas para saber lo que está vigente y lo que se halla derogado, porque no siempre es fácil conocerlo".

Propone cono remedio hacer ui:a o más compilaciones ordenadas de nuestras leyes, que comprendiendo los distintos ramos de la Administración, y partiendo de un buen sistema de clasificaciones, divisiones y subdivisiones, omitieran todo to derogado explícita o implícitamente, dejarán a un lado todo lo inútil y redactarán, con orden, precisión y claridad, lo vigente. Sería, sin duda, difícil la obra, exigiría mucha atención, muchos estudios y muchos conocimientos; tendría que ser confiada a personas muy capaces, pero sería fecundísima en buenos resultados...; contribuiria, en primer término, a regularizar la Administración, lo que no se conseguiría por completo siguierito por el camiro que llevamos.

$E_{s}$ verdad-dice-que las necesidades nuevas vendrían a exigir nuevas disposiciones; pero... apéndices hechos oportunamente portían por mucho tiempo hacer necesarias nuevas compilaciones y, cuando llegara el dia en que por cambios profundos sucesivos apareciera la necesidad de substituir a las compilaciones antiguas oiras nuevas, mucho se habría adelantado. El Gobierno sólo es el que puede hacer lo que deseamos; los pariticulares no tienen ni los medios ni la autoridar bastante para hacerlo. 
recen en otros artículos de la Serna (I), pero no quiero cansar vuestra atención ni tampoco distraeros un momento más, para que podáis oír, como antes decía, voces más autorizadas que la mía. No quisiera, sin embargo, terminar este cen-

(1) De las exposiciones razonadas sobre los proyectos de ley. Rv. Generall de Legislación y Jurisprudencia. T. XVII, pág. 90.

Plantea La Serna en este trabajo el problema del valor juridico-doctrinal de las exposiciones de motivos, con ocasión de presentar a las Cortes el Proyecto de Ley. Hipotecaria.

Cita opiniones de Séneca y de Bacon, que mantienen la tesis de que las leyes no fueran razonadas. El primero decía: que las leyes debían ser buenas y mandaren, no que discutieren. Esta idea senequista pasa al Fuero Juzgo (Ley 2." del Título r. ${ }^{\circ}$, Libro $\mathbf{1}^{\circ}$, que trata del legislador).

Recuerda La Serna cómo Bacon, que se muestra contrario a los prólogos, porque iritroducen leyes disputadoras, no preceptivas, llega, sin embargo, a admitirlos, no a título de explicación de las mismas, sino para aconsejarlas al Parlamento y para satisfacer al pueblo.

Recuerda asimismo la opinión de Bentham de que al lado de la Ley haya un comentario'razonado. Se pregunta si conviene seguir "el reino de Baviera, que dió el ejemplo de poner un comentario oficial, cosa semejante a la que se hizo en tiempo de Alarico en el Breviario de Aniano".

La Serna estima que cuando el estudio de las leyes se hace acompañándolas de la investigación de los principios racionales que las justifican, "desaparece la aridez, que fatiga a los que la cultivan; la participación que se tiene en los secretos del legislador, alienta para seguirlo hasta las últimas consecuencias que emanan de los principios fundamentales de su obra; la imaginación se pome en actividald, el talento se ejercita y la memoria no necesita hacer tantosi esfuerzos, porque la filosofía de la ley, más fácil de retener que su texto, impide que éste se olvide por completo".

Bentham decía que las razones son una especie de memoria técnica.

Cree La Serna que el "acto de revelar el espíritu de la ley, cuando esta revelación precele del que la forma, evita además interpretaciones arbitrarias e inmotivadas". Admite, pues, las exposiciones de motivos, pero desecha por concisión' torlas la:s' que estén dentro ide la misma ley, bien sea en un preámbulo, bien mezcladas con las reglas que establece. Porque "toda palabra que no $e_{s}$ absolutamente indispensable en el texto de la ley, sobne rebajar su majestad, daña a su inteligencia".

Tampoco es partidario de los comentarios legales escritos por el legislador. Cree, en cambio, en la conveniencia ide publicar las discusiones de las leyes, tanto las de corporaciones científicas como las de los Cuerpos políticos. Hace especial alusión a aquéllas:

"Las discusiones de los Cuerpos científicos nunca han visto en España la luz pública; discusiones concienzudas y modestas, al mismo tiempo, que difíciles..., las Luminosas observaciones de una sesión se olvidan con las impresiones de las sesiones que siguen; por $l_{0}$ mismo que no hay en estas reuniones la pretensión de grandes formas, ni de producir efectos deslumbradores, ni de arrebatar aplausos, las neflexiones son concretas, la polémica, aunque anima'la a veces, no es apasionada, todas las opiniones son escuchadas, y los mismos que en el campo de la política aparecen más alejados en opiniones, se entienden con facitidad en las pacíficas tareas de la ciencia a que se hallan consagrados."

Recomienda, no obstante, que de eistos debates no se tomen notas taquigráficas, sino extractos, pue:s aquéllas retraerían tal vez de hacer observaciones a jurisconisultos eminentes, pero modestos y tímidos.

Termina diciendo que "los motivos de la ley no son la ley..., su autoridid es meramente doctrinal y no se puede confundir el valor doctrinal de estas opiniones con el legal que tendría un comentario auténtico; serán, sin duda, de gran peso en el forc, pero no podrán forzar la convicción de los magistrados". 
tenario, precisamente matemático de 1843 , sin apuntar el hecho de la coincidencia con el alborear de la administración española moderna.

Recordaba ayer el maestro Gascón la frase de Oliván según la cual la administración tenía una fuerza sustantiva; se decía que el Gobierno forma la administración, pero que la administración sostiene a los Gobiernos. Tan es así, que un historiador alemán, refiriéndose a aquella época en España, estudiando la guerra civil, nos dice cómo uno de los factores que intervinieron para el triunfo de los vencedores fué precisamente el tener en sus manos la administración, no sólo la administración central, sino también una gran parte de la administración local. Así, pues, aun en estos momentos de escaso desarrollo de la administración, cuando comenzaba a incubarse, vemos que desde el punto de vista práctico y político aquélla tiene ya cierta densidad; desde el punto de vista científico se escriben sobre la misma obras como la que acabamos de hacer referencia. 